\title{
Maps don't lie
}

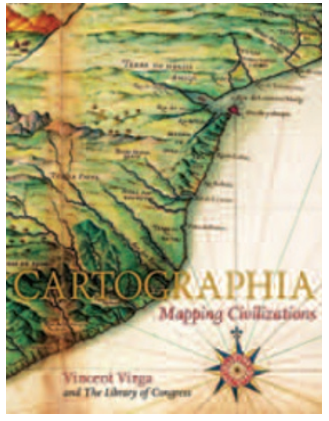

\section{CARTOGRAPHIA BY VINCENT VIRGA AND THE LIBRARY OF CONGRESS}

Little, Brown and Company: 2007. 266 pp. $\$ 60.00$
Cartographia astounds as a rich and diverse compilation of maps. Even while flipping through its pages quickly, one cannot but be reminded that maps are more than mere tools for representing various aspects of the natural or urban landscape. They are emblems of human endeavour and works of art, as well as inherently selective and biased graphic interpretations, as the book points out. It is precisely these characteristics that endow maps with the potency to expose the many facets of civilizations and the intricacies of history.

The four chapters of Cartographia take the reader through more than 200 maps, reproduced from the collection of the Map Division of the Library of Congress in Washington DC, arguably the largest collection of maps in the world. The book includes the conventional two-dimensional representations of natural or urban landscapes on media ranging from clay to papyrus. But other types of maps are also pictured, such as a relief map on an ancient Chinese incense burner or the wooden sculpture of an ancestral female figure made by the Tabwa people (Congo region, central Africa), containing geographic as well as mythological information. And the "Map of the Human Genome" or the "View of the World from Ninth Avenue" in the Epilogue challenge and expand the reader's traditional conceptions of what a map is.

Cartographia offers glimpses into the complexities of history and civilizations. For example, maps such as one from 1892 showing segregated enclaves of Indian reservations within the limits of the United States portray the global inequities in power distribution that have characterized much of documented history. And as Vincent Virga poignantly observes, the story of how colonialism converted Africa's history into tragedy is told most brilliantly in maps.

Inclusion of this book into school history curricula could shatter the common association of history with rote memorization of facts, while providing a novel perspective on the astonishing breadth of art.

Ninad Bondre

\section{Students, seals and science}

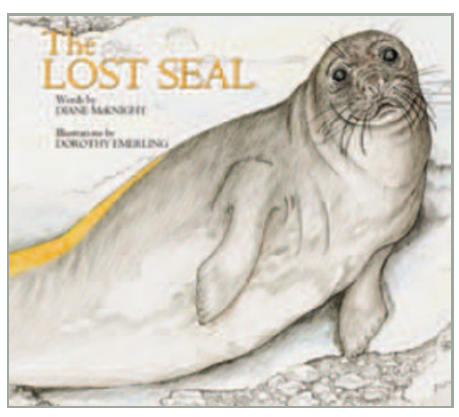

\section{THE LOST SEAL BY DIANE MCKNIGHT}

Moonlight Publishing: 2006. 40pp. \$19.95

Although most people can imagine that life on the ice can be difficult, actual glimpses into the daily lives of the denizens of Antarctica (and the humans that visit them) are rare. The Lost Seal, which is intended for readers between the ages of 9 and 12, recounts the adventures of polar scientists and a young wayward seal.

This story engages the reader from the start, challenging the common misconception of deserts as hot places full of cacti and snakes. Aridity is the key, and some of the world's most unusual deserts are found in the Dry
Valleys of Antarctica. McKnight shares a story based on her real-life experience of a seal who had wandered away from the coastal ocean into one of the dry valleys. The scientists (and the readers) are forced to ask why the seal strayed so far from the shore, and how it might 